\title{
VIRUS DEL PAPILOMA HUMANO, RESPUESTA INMUNE Y CÁNCER CERVICAL: UNA RELACIÓN COMPLEJA
}

\section{Human papillomavirus, immune response and cervical cancer: a complex relationship}

Olga L. Rincón, BSc,* Luis René Pareja, M.D.**, Sergio Jaramillo, M.D.***, Beatriz H. Aristizábal, MSc, PhD, PdF****

Recibido: marzo 15/07 - Revisado: agosto 13/07 - Aceptado: agosto 17/07

\section{RESUMEN}

El cáncer de cuello uterino se considera como un grave problema de salud pública con una alta incidencia en los países en desarrollo. La infección, permanencia y replicación del virus de papiloma humano (HPV, por sus siglas en inglés) de alto riesgo a nivel cervical están relacionadas con el desarrollo del cáncer de cuello uterino. En condiciones normales, el sistema inmune es capaz de controlar y eliminar la infección por acción de la inmunidad innata, la activación de una respuesta tipo celular y la creación de anticuerpos dirigidos principalmente a las proteínas de la cápside del virión (L1 y L2). A pesar de toda la maquinaria de protección inmune del hospedero, el virus posee estrategias de evasión, conservando un número reducido de copias en las células basales proliferantes y aprovechando la corta vida natural del queratinocito. En esta revisión se tratarán los diferentes mecanismos inmunológicos del hospedero en la respuesta a la infección por el HPV.

\footnotetext{
* Laboratorio de Biología Molecular.

** Ginecólogo oncólogo.

Unidad de Cancerología Hospital Pablo Tobón Uribe.

*** Jefe de Laboratorio Clínico y de Patología.

Laboratorio Clínico y de Patología Hospital Pablo Tobón Uribe.

**** Laboratorio de Biología Molecular

Correspondencia: calle 78B \# 69-240, Medellín.

Correo electrónico: baristizabal@hptu.org.co
}

Palabras clave: virus del papiloma humano, inmunidad, infección cervical, cáncer cervical, queratinocitos.

\section{SUIMMARY}

Cervical cancer is considered to be a serious public health problem having a high incidence in developing countries. High-risk cervical human papillomavirus (HPV) infection, permanence and replication are closely related to the development of cervical cancer. The immune system is able to control and clear such infection in normal conditions by innate immunity action, activating a cellular response and creating antibodies, mainly directed against virion capsid proteins (L1 and L2). In spite of the host's entire immune protection machinery, the virus can take evasion strategies, maintaining a reduced number of copies in proliferating base cells and taking advantage of the keratinocyte's short natural life. This review attempts to show the host's different immunological mechanisms elicited in response to HPV infection.

Key words: human papillomavirus, natural and acquired immunity, cervical infection, cervical cancer, keratinocyte. 


\section{INTRODUCCIÓN}

En la última década, los estudios epidemiológicos apoyados por técnicas moleculares han confirmado el papel causal de ciertos tipos de HPV, evidenciando la presencia de su ácido desoxirribonucleico (ADN) en el 99,7\% de los cánceres cervicales. Además, se ha definido un modelo molecular para la carcinogénesis inducida por el HPV. ${ }^{1}$

Los estudios sobre historia natural de la infección por HPV demuestran que un número importante de mujeres jóvenes se infecta en las edades de mayor actividad sexual ( $<30$ años para HPV de alto riesgo); la frecuencia de infección puede llegar hasta un 50\% en las mujeres adolescentes y adultas jóvenes que adquieren la infección en los primeros cuatro a cinco años de comenzar su vida sexual. De estas mujeres, hasta un 25\% desarrollan lesiones escamosas epiteliales de bajo grado (low squamous intraepitelial lesion, LSIL). No obstante, el 90-95\% de las infecciones se resuelven espontáneamente, sin ningún tratamiento; al igual que el 95\% de los casos de LSIL que se detectan en mujeres jóvenes. ${ }^{2,3}$

La persistencia del HPV ocurre en un 5\% de las mujeres después de los 35 a 40 años. Este subgrupo constituye el de mayor riesgo para desarrollar lesiones escamosas intraepiteliales de alto grado (high squamous intraepitelial lesion, HSIL) y cáncer cervical. $^{4}$

El objetivo de esta revisión es mostrar la dinámica de estos eventos moleculares que ocurren a nivel cervical y hacen posible que la infección por HPV pueda progresar en cáncer.

\section{Caracterización del virus}

Los papilomavirus humanos (HPV), miembros de la familia Papovaviridae, son pequeños virus de ADN circular encapsulado de escasamente 8.000 pares de bases. Su estructura la comparten más de 100 tipos secuenciados hasta la fecha. Estos virus constan de varios genes $\mathrm{u}$ open reading frames (ORF) de dos tipos diferentes: hasta ocho genes de expresión temprana o early (E1-E8), cuya expresión se traduce en proteínas implicadas en la regulación y replicación viral, y dos genes de expresión tardía o late (L1, L2), cuya expresión genera las proteínas para el ensamblaje de la cubierta viral, la cápside. Una región de control, denominada long control region (LCR), será la encargada de controlar la expresión de los genes tempranos E6 y E7. ${ }^{5}$

\section{Clasificación de los HPV y su relación con la patología}

Según su riesgo oncogénico, se clasifican en dos tipos: HPV de bajo riesgo (HPV-BR): 6, 11, 40, 42, 43, 44, 54, 61, 70, 72 y 81; y HPV de alto riesgo (HPV AR): 16, 18, 31, 33, 35, 39, 45, 51, 52, 56, 58, 59, 68, 73, y $82 .{ }^{6}$ Ciertos tipos virales pueden aparecer en lesiones cancerosas como resultado de una coinfección y no ser los agentes etiológicos causales de la transformación tumoral. Como es lógico, los estudios epidemiológicos atribuyen variaciones poblacionales importantes en la prevalencia y relación causa-efecto de los diferentes tipos virales, sin embargo, es indudable la gran prevalencia o implicación en las patologías de alto grado y carcinomas que tienen los tipos 16, 18, 56 y la que los tipos 6 y 11 tienen en las patologías de tipo condilomatoso. ${ }^{6}$

\section{Inmunidad en la infección por HPV}

La interrelación entre HPV y hospedero es compleja y variada. En el caso del papilomavirus, no se ha encontrado un receptor celular específico que permita parar la infección por bloqueo del mismo. Tanto el reconocimiento de la infección viral por la célula hospedera como el tropismo específico de cada tipo viral van a determinar los efectos citopáticos en los tejidos específicos. ${ }^{7-9}$

Los HPV, al igual que otros virus, aprovechan la maquinaria celular para replicarse. En determinadas circunstancias fisiológicas de "permisividad inmunológica" y tras un período de persistencia de la infección, generalmente largo, las partículas de ADN viral que se encuentran en forma episomal, sufren un proceso de integración dentro del genoma celular y, con ello una serie de acontecimientos que conducen a un bloqueo de proteínas con funciones 
importantes en el ciclo celular (p53 y Rb) y, como consecuencia, alteraciones en el crecimiento normal y diferenciación del epitelio cervical, seguidas de una acumulación de errores genéticos (clastogénesis), base de la transformación tumoral. ${ }^{2,5, ~ 6, ~ 10-12 ~} \mathrm{La}$ prolongación de la respuesta inmune en el tiempo y la protección frente a futuras infecciones requieren, sin duda, mecanismos de inmunidad específica. ${ }^{13} \mathrm{La}$ inmunidad protectora resulta de la interacción entre la inmunidad innata y la inmunidad adaptativa.

\section{Respuesta inmune innata}

A escala cervical, como defensa, tras la primera infección de las células del epitelio por HPV, se desencadena una serie de respuestas inespecíficas acompañadas de procesos inflamatorios, quimioatracción de neutrófilos, activación de macrófagos, intervención de células asesinas naturales (NK), de anticuerpos naturales, e incluso del sistema del complemento, que formarán una primera barrera defensiva de inmunidad inespecífica. Las células reticulares de Langerhans (LC), y algunos queratinocitos funcionan como células presentadoras de antígenos (APC). Estas células fagocitan las partículas virales para digerirlas en endosomas y comenzar un proceso de activación, que incluye la presentación en superficie de cadenas polipeptídicas del antígeno junto con HLA clase II, CD40 y B7, así como la migración a los ganglios linfáticos locales. ${ }^{14,15}$ Las LC junto con el HLA, moléculas coestimuladoras (CD80, CD86 y CD40), y citoquinas como IL-12 o IL-10, activan los LT nativos y dirigen su diferenciación hacia células efectoras. ${ }^{16}$ La información adquirida por las células dendríticas (DC) dirige la inmunidad mediada por LT ayudadores o citotóxicos, Th1 o Th2. ${ }^{17-19}$

Las DC emplean un patrón de reconocimiento por medio de receptores tales como los de la familia toll-like receptor (TLR), que detectan la infección. Además, ellas juegan un papel crítico en la inducción natural de la respuesta inmune adaptativa. Los TLR señalan principalmente la vía de adaptador MyD88 para activar respuestas innatas. Estas respuestas innatas incluyen la producción de un número de citoquinas y quimoquinas que juegan un papel clave en la inducción de inmunidad adaptativa y en la regulación del linfocito Th1. ${ }^{20}$

La infección viral de los queratinocitos contribuye a la inmunodeficiencia local mediante la inhibición de la producción de moléculas solubles y de membrana, importantes para la migración y función de las células presentadoras de antígenos. ${ }^{21-23}$

Las células NK inducen la apoptosis de las células infectadas por el virus y de las células tumorales, gracias a los activadores e inhibidores de los receptores killer (KIR). Así se da la unión entre KIR y el alelo específico de HLA clase I, complejo que es reconocido y que regula la inmunidad mediada por las NK. Las células normales que expresan abundantes moléculas de HLA clase I son reconocidas por KIR e inhiben la activación de las NK; en células infectadas por virus y células tumorales la expresión del HLA disminuye, llevando a la activación de las células NK y a la citólisis. ${ }^{24-28}$

Las LC son células dendríticas inmaduras de origen mieloide que residen en el epitelio escamoso, incluyendo piel y mucosa genital. Las LC reconocen agentes patógenos, capturan antígenos por micropinocitosis o receptores de manosa, procesan las proteínas capturadas y las transforman en péptidos inmunogénicos, migran del tejido a los nódulos linfáticos y presentan los péptidos en el contexto de moléculas del complejo mayor de histocompatibilidad a los linfocitos T, iniciando así la respuesta inmune antígeno específica. ${ }^{16}$ Figura 1

\section{Citoquinas}

Cuando se produce daño en el tejido, el sistema inmune innato envía moléculas señales que no se encuentran normalmente, como estructuras ricas en manosa y proteínas de choque térmico que, junto con las células dendríticas (DC), inician la coordinación de células efectoras del sistema inmune como monocitos, macrófagos, polimorfonucleares (PMN) y células NK para la protección del tejido mucoso. Su activación induce la producción de moléculas 


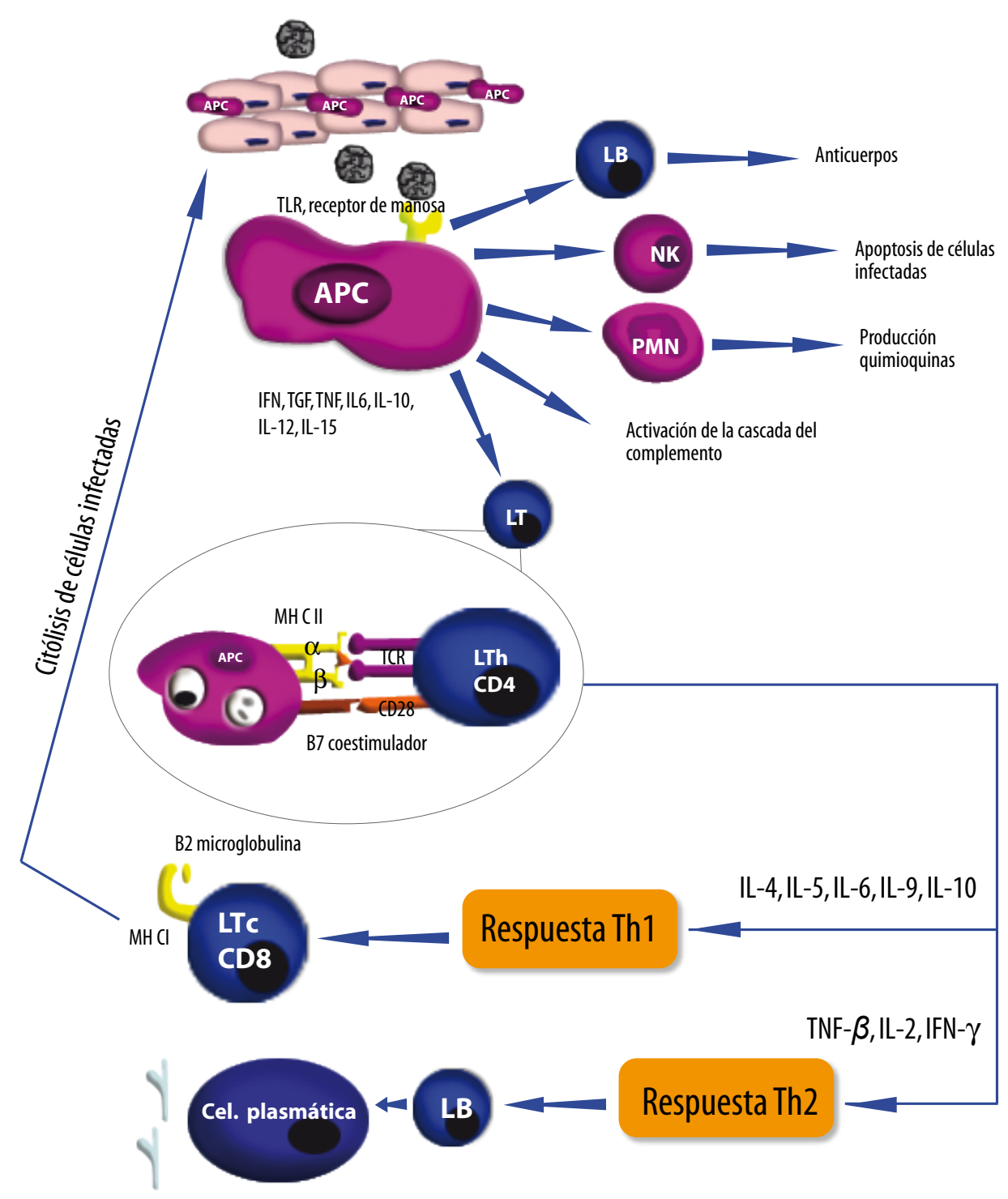

Figura 1. Respuesta inmune en la infección por HPV.

coestimuladoras como las defensinas, interleuquinas (IL), interferones (IFN), factor de crecimiento transformante (TGF) y factor de necrosis tumoral (TNF), los cuales ejercen un control directo sobre las células infectadas. ${ }^{29,30}$

Las alfa defensinas humanas 1-3 (HD1-HD3), conocidas como péptidos de neutrófilos humanos (HNP) y la alfa defensina humana 5 (HD5), están presentes en el tracto genital femenino en niveles capaces de inhibir el HPV in vitro, sugiriendo que pueden servir como barrera natural para la transmisión sexual del HPV y como microbicidas de amplio espectro. HD1, HD3 y HD5 son potentes antagonistas de la infección por los HPV cutáneos y mucosos. Por el contrario, las beta defensinas humanas 1 y 2 tienen una pobre o nula actividad anti-HPV. ${ }^{31}$

Los linfocitos $\mathrm{T} \mathrm{CD}^{+}{ }^{+}$activados evolucionarán hacia linfocitos $\mathrm{T}$ ayudadores (Th) en el contexto local de expresión de ciertas IL, de modo que si predomina la de tipo IL-12, se promoverá la diferenciación hacia una vía Th1 que inducirá la activación y proliferación de los linfocitos $\mathrm{T} \mathrm{CD}^{+}{ }^{+}$citotóxicos específicos $(\mathrm{CTL}+8)$ y la producción de IL-2 e 
Interferón- $\gamma$ fundamentalmente; por el contrario, si en el contexto local no se expresa IL-12, se promoverá la vía Th2 que inducirá la activación y expansión de linfocitos $\mathrm{B}$, los cuales evolucionarán, diferenciándose, hacia células plasmáticas productoras de anticuerpos (Ac) frente a las proteínas virales; por otra parte, se inducirá expresión de interleuquinas del tipo IL4, IL5, IL6, IL10. Figura 1

La IL-10, citoquina del tipo Th2, tiene efecto supresor en la inmunidad mediada por células. La resistencia a la apoptosis a través de la vía del Fas podría incapacitar muchos tipos de cáncer para escapar del sistema inmune. ${ }^{32}$

El TGF- $\beta$, TNF, y los IFN tipo I ( $\alpha$ y $\beta$ interferón), son productos de varios tipos de células epiteliales y tienen capacidad para inhibir la proliferación de los queratinocitos normales e infectados con HPV, así como también tienen la capacidad de inhibir la expresión de los genes E6 y E7 del HPV. ${ }^{33}$

TGF- $\beta 1$ puede ser un regulador autocrino de la expresión génica del HPV de las células epiteliales. TNF producido por los queratinocitos puede tener efecto antiproliferativo en las células infectadas por HPV bloqueando el crecimiento en G0 y G1 del ciclo celular. Los receptores solubles tipo I y II de TNF en suero se encuentran elevados en pacientes infectados con HPV 16 ó HPV 18 asociados a carcinoma cervical. ${ }^{33}$ Figura 1

La expresión molecular de HLA es sobrerregulada generalmente por las citoquinas asociadas al proceso inflamatorio. Sin embargo, la genética de HLA puede también influir en la susceptibilidad a la infección o la capacidad de eliminar el HPV y de evitar así la persistencia, que es el factor de riesgo dominante para la progresión. . $24,25^{2}$

\section{Inmunidad celular}

Una vez las APC están activadas, son reconocidas por linfocitos $\mathrm{T} \mathrm{CD}^{+}{ }^{+}\left(\mathrm{CD}^{+}{ }^{+} \mathrm{T}\right)$ que serán activados, únicamente, si existe reconocimiento de todas y cada una de las moléculas de superficie implicadas: HLA clase II a través del propio CD4, el polipéptido viral mediante el TCR, CD40 a través de CD40- ligando y B7 mediante CD28. Una vez activados, los linfocitos T y B deberán reconocer a las células infectadas, ahora en el contexto del HLA clase I, de lo contrario, no se producirá el proceso de expansión clonal necesario para la elaboración de una respuesta inmunológica eficaz. Los CTL +8 tendrán la capacidad de actuar frente a la infección viral establecida, mientras que las células B plasmáticas producirán anticuerpos contra las sucesivas infecciones por HPV. ${ }^{16,17}$ Figura 1

La mayor parte de linfocitos T (LT) en el epitelio cervical pertenecen al subgrupo de supresor/citotóxico CD8 y, en menor cantidad, al subgrupo de ayudante/inductor CD4, ambos se pueden encontrar en las capas básicas del epitelio escamoso y también pueden estar en grandes números en la zona de transformación ectocervical. La expresión de la molécula CD25 (receptor de IL-2) es un signo conocido de activación celular.

En mujeres sanas, el estímulo de los linfocitos periféricos es dado por los fragmentos de los antígenos tempranos E6, E7, y por los antígenos tardíos L1 del HPV que inducen la proliferación de células específicas, sobre todo células de memoria. ${ }^{21,22}$

Una infiltración celular, dada esencialmente por CD4 a la porción C terminal de E2 y macrófagos, con frecuencia se encuentra en condilomas bajo la regresión espontánea, ${ }^{18}$ mientras en pacientes con inmunodeficiencia celular adquirida o iatrogénica se observa un mayor predominio de lesiones relacionadas con HPV, así como una mayor progresión hacia lesiones preinvasivas.

A nivel de cérvix un infiltrado leucocitario a expensas de CD4 favorece la regresión, pero si el predominio es de CD8 puede significar persistencia y la progresión de la infección viral. 13, 34, 35

Las respuestas generadas por la célula T, después de la infección, podrían desempeñar un papel de protección contra la progresión de la infección y lesiones tempranas. Debería entonces considerarse el desarrollo de inmunoterapias que vayan dirigidas a la estimulación de los linfocitos $\mathrm{T} \mathrm{CD}^{+}$para el manejo de la enfermedad preinvasiva. ${ }^{36}$ 
Las células T activadas inicialmente al contacto con el Ag pueden controlar el reto inicial del virus, pero estas mueren y hay una diferenciación de subclases (memoria), las cuales conforman la respuesta inmune tardía. ${ }^{37}$

Se cree que el reconocimiento de los antígenos blanco de HPV por las células T será la clave para investigar sobre la resolución completa de la infección. ${ }^{34}$ La investigación de la respuesta de los LT frente a los oncogenes de HPV en neoplasia cervical, se ha centrado en gran parte en la actividad de los LT en sangre periférica. ${ }^{36,38}$ Así, LTh, ${ }^{37,39,40}$ LT citotóxi$\cos (\mathrm{CTL}),{ }^{21,41,42}$ interferón y el HLA43 demuestran actividad de E7 en bajos niveles en pacientes con lesiones o cánceres HPV-persistentes. Los LTC son más abundantes en el sitio de la exposición al Ag44 y tienen un papel crítico en la respuesta y evolución. Hay algunas evidencias que muestran el papel de células T citotóxicas contra oncogenes virales en la inmunidad del tumor de $\mathrm{HPV}^{45}$

\section{Inmunidad humoral}

Existe una asociación positiva entre la detección de los anticuerpos HPV (principalmente para HPV 16) y el riesgo de neoplasia cervical, considerándose la detección de anticuerpos HPV como un marcador de infección activa o de exposición pasada a HPV. ${ }^{46,47}$

Los anticuerpos contra HPV son altamente específicos. Estos anticuerpos, particularmente los que tienen como diana las proteínas de la cápside del virión (L1 y L2), pueden ser efectivos para prevenir la infección, es comúnmente aceptado que estos anticuerpos no tienen efectos importantes de regresión sobre las infecciones establecidas o lesiones cervicales. Menos claro es si los anticuerpos contra un tipo de HPV protegen contra la nueva infección con el mismo u otro tipo de HPV estrechamente relacionado y, si es así, si esta protección es relacionada con subconjuntos de anticuerpos específicos, por ejemplo, IgG y subclases e IgA. ${ }^{48}$

Los anticuerpos específicos para la proteína principal de la cápside L1 de HPV 16 se detectan entre cuatro meses y cinco años después de la infección primaria, ${ }^{47}$ solamente algunas personas infectadas permanecen seronegativas. Parece que la seroconversión es lenta y que la exposición antigénica conduce el proceso, puesto que se asocia a una carga y a una persistencia viral más altas de la infección. ${ }^{49}$ Otros estudios demostraron que los anticuerpos cápside-específicos de HPV, generados por la infección natural, no son protectores en infecciones subsecuentes, puesto que la seropositividad no se asocia a un riesgo disminuido de la reinfección con el tipo homólogo o los tipos genéticamente relacionados de $\mathrm{HPV}{ }^{50}$ Los anticuerpos específicos para E7 aparecen solamente con el desarrollo del cáncer, aunque E7 se exprese en las células preneoplásicas. ${ }^{51}$

\section{Estrategias virales de evasión inmune}

El largo período de latencia desde la infección hasta la resolución de la enfermedad indica que el HPV ha evolucionado para escapar a la respuesta inmune.

Cuando el HPV llega al epitelio cervical se ubica en la zona de trasformación, allí es posible definir una población viral no productiva, en la cual se mantiene la replicación del ADN viral en un número de copias bajo (30-50 copias por célula infectada), en forma extracromosómica, llamados episomas que se estructuran con base en histonas y material genético. ${ }^{52}$ Se postula que durante esta etapa se asegura que el ADN viral se distribuya difusamente por las células basales proliferantes y que al mantener un número reducido de copias se impida la activación de la respuesta inmune..$^{53}$ Las células basales proliferantes ascienden a los estratos parabasal y espinoso, amplificándose la expresión de genes virales tempranos a través de la región no codificante (URR), los cuales permiten producir ADN a cientos de copias por célula, a esta etapa en el ciclo viral se le conoce como la fase vegetante, proliferante o productiva. ${ }^{53}$

El HPV aprovecha la corta vida natural del queratinocito para la replicación viral y así la infección pasa desapercibida por el sistema inmune. La célula muere y aun estando infectada no se generan señales 
de peligro por daño o muerte celular que activen los procesos de inflamación. ${ }^{54}$

Otros mecanismos de evasión pueden ocurrir cuando en ciertos casos los virus presentan antígenos de superficie muy variables que conducen a la síntesis de un exceso de anticuerpos, no neutralizantes, que pueden llegar a interferir con los que sí tienen esa capacidad de neutralización, o mediante la depleción de la expresión de moléculas del complejo mayor de histocompatibilidad, lo cual permite que pasen desapercibidos por el sistema inmune. ${ }^{55,56}$

Muchas infecciones víricas toman como blanco a células inmunocompetentes como $\mathrm{CD}^{+} \mathrm{T}$ y células de Langerhans, comprometiendo así la eliminación de la infección por alteración de los mediadores en el montaje de la respuesta inmune o con la inducción de alteraciones funcionales en las LC.

La proteína E7 del HPV16 inhibe la inducción de INF $\alpha$, de este modo interfiere con la eliminación efectiva del HPV y logra completar su ciclo de vida.

La divergencia de los residuos expuestos en la superficie de L1 se relaciona con una evasión de la respuesta inmune por alteración de los epítopes neutralizantes. Igualmente los altos niveles de mutaciones de la cápside del virus escapan a la respuesta de las células dendríticas del sistema inmune innato en el cáncer cervical. ${ }^{53,54}$

La persistencia viral, progresión de la enfermedad y transformación maligna pueden deberse a mecanismos de evasión de citoquinas (TGF-B, TNF, IL-1, IFN tipo I, IFN- $\delta$ ) usados por el virus.

La activación del fosfoinositol 3-kinasa define el mecanismo de escape usado por el HPV, y su inhibición podría servir como un blanco efectivo para realzar la respuesta inmune. ${ }^{57}$

\section{Mecanismos de oncogénesis}

Los HPV infectan las células basales del epitelio cervical y aprovechan el proceso de diferenciación del epitelio para sintetizar las proteínas que les permitirán ensamblar nuevas partículas víricas. Las células epiteliales infectadas activan su mecanismo de defensa celular consistente en una revisión de la secuencia del ADN antes de dividirse. Este proceso ocurre durante una fase del ciclo celular y está dirigido por una cascada de proteínas entre las que se destacan la p53 y la proteína Rb. ${ }^{1}$ Cuando la célula localiza el ADN viral, en un proceso perfectamente regulado, intenta reparar el error y dado que este ADN es excesivamente grande como para ser eliminado, p53 y Rb dirigen la célula infectada a una "muerte celular programada" por apoptosis, evitando así que esta célula sirva de propagadora de la infección. Los genes E6 y E7 transcriben un producto cuya traducción resultará en la producción de las proteínas E6 y E7 que respectivamente serán capaces de bloquear a p53 y Rb del ciclo celular y protegerse de la muerte de la célula por apoptosis, pudiendo de este modo seguir utilizándola como centro de producción de partículas virales. Por esto E6 y E7 deben considerarse, en todos los efectos, oncogenes virales. Parece claro que el mecanismo de oncogénesis por HPV comienza con la expresión de E6 y E7. Las infecciones con alta carga viral, tienen un riesgo más alto de transformación neoplásica. Sin embargo, ciertas infecciones persistentes con baja carga viral generan un fenotipo tumoral efectivo, en la mayoría de los casos una porción del ADN viral se fragmentaba por la región E2 perdiendo su capacidad de actuar sobre la región reguladora URR y dando la orden de que esta mantenga reprimida la expresión de E6 y E7, de esta forma, una pequeña cantidad de virus estará desregulada y producirá grandes cantidades de proteína E6 y E7 que iniciarán el proceso de bloqueo de p53 y Rb de modo altamente efectivo. ${ }^{53}$

El desarrollo de las técnicas de biología molecular y su amplio uso en estudios epidemiológicos han permitido estimar que entre un 2 y un $20 \%$ de la población femenina mundial es portadora del HPV en el cuello uterino. Además, bajo ciertas condiciones estas infecciones por HPV pueden convertirse en persistentes con capacidad de inducir o aumentar el riesgo de cáncer de cérvix. 


\section{HPV como causa etiológica necesaria del cáncer de cérvix}

La asociación entre HPV y cáncer de cérvix se considera causal. La naturaleza causal de esta asociación se basa en: 1) La detección regular de ADN viral en las células neoplásicas de los tumores; 2) La demostración de la expresión oncogénica viral (genes E6 y E7) en tejido tumoral pero no en tejido sano; 3) Las propiedades de transformación de los genes E6 y E7; 4) El requerimiento de la expresión de E6 y E7 para mantener el fenotipo maligno de líneas celulares de carcinoma cervical; 5) La interacción de las oncoproteínas virales con las proteínas reguladoras del crecimiento de las células hospederas; y 6) Los resultados de múltiples estudios epidemiológicos realizados en distintas poblaciones, con distintos diseños, demuestran de forma coherente e inequívoca que las infecciones por ciertos tipos de HPV son el principal factor de riesgo para el desarrollo de cáncer cervical.

Estudios más potentes, en los que se han utilizado técnicas de amplificación, indican que la prevalencia de ADN de HPV en el cáncer de cérvix es sistemáticamente superior al 98\%, con varias series que encuentran secuencias virales en la totalidad de los casos, mientras que la detección en los controles es sumamente menor (5 al 20\%). Se estima que el número de mujeres a escala mundial con ADN-HPV es de 291 millones, y alrededor de 105 millones de mujeres han tenido infección por lo menos una vez en su vida con HPV16 o HPV18, los tipos oncogénicos más comunes en carcinoma cervical. ${ }^{58}$

Dada toda esta evidencia virológica, clínica, epidemiológica y molecular acumulada existe un consenso multidisciplinario de la comunidad científica, que considera la infección por ciertos tipos oncogénicos de HPV como la causa etiológica necesaria del cáncer de cuello uterino.

\section{CONCLUSIONES}

El sistema inmune tiene la capacidad de detectar y neutralizar o eliminar todo agente externo que represente una amenaza para el organismo. Su res- puesta es compleja y está basada en un sinnúmero de señales que activan una o varias vías de rechazo $y$ ataque al agente externo. Cuando la integridad de dicha respuesta no está comprometida, el éxito es seguro y el organismo no ve afectada su función.

La infección por virus de papiloma, en la mayoría de las mujeres jóvenes sin ningún compromiso inmune, pasa desapercibida. La respuesta dada por el $\mathrm{LT} \mathrm{CD}^{+}{ }^{+}$al reconocer el polipéptido viral mediante el TCR, la activación y proliferación de los LT CD8 ${ }^{+}$, la producción citoquinas y por último la generación de anticuerpos logran limitar la infección por el virus. Sin embargo, este cuenta con estrategias de evasión como lo son las proteínas virales tempranas E6 y E7 capaces de bloquear la apoptosis celular, el hecho de mantener una población viral no productiva con índices de replicación de ADN bajos y la utilización de los queratinocitos que al tener un período de vida corto y al infectarse por el virus no desencadenan una respuesta inflamatoria que alerte al sistema inmune.

La confrontación entre el sistema inmune y la infección por HPV es compleja, los dos poseen mecanismos altamente efectivos para sobreponerse al otro y la más mínima ventaja o defecto en el sistema inmune es aprovechada por el virus para replicarse y desarrollar todo su potencial oncogénico e inducir el cáncer.

\section{REFERENCIAS}

1. Muñoz N, Castellsagué X, de González AB, Gissamann L. Chapter 1: HPV in the etiology of human cancer. Vaccine 2006;24S3:S1-S10.

2. Moscicki AB. Human papilloma virus, papanicolaou smears, and the college female. Pediatr Clin North Am 2005;52:163-77.

3. Goldie SJ, Grima D, Kohli M, Wright TC, Weinstein M, Franco E. A comprehensive natural history model of HPV infection and cervical cancer to estimate the clinical impact of a prophylactic HPV-16/18 vaccine. Int J Cancer 2003;106:896-904.

4. Moscicki AB, Hills N, Shiboski S, Powell K, Jay $\mathrm{N}$, Hanson E, et al. Risks for incident human 
papillomavirus infection and low-grade squamous intraepithelial lesion development in young females. JAMA 2001;285:2995-3002.

5. zur Hausen H. Papillomaviruses and cancer: from basic studies to clinical application. Nat Rev Cancer 2002;2:342-50.

6. Doorbar J. The papillomavirus life cycle. J Clin Virol 2005;32(Suppl 1):S7-15.

7. Smyth LJ, Van Poelgeest MI, Davidson EJ, Kwappenberg KM, Burt D, Sehr P, et al. Immunological responses in women with human papillomavirus type 16 (HPV-16)associated anogenital intraepithelial neoplasia induced by heterologous prime-boost HPV-16 oncogene vaccination. Clin Cancer Res 2004;10:2954-61.

8. Scheurer ME, Tortolero-Luna G , Adler-Storthz K. Human papillomavirus infection: biology, epidemiology, and prevention. Int J Gynecol Cancer 2005;15:727-46.

9. Abdel-Hady ES, Martin-Hirsch P, Duggan-Keen M, Stern PL, Moore JV, Corbitt G, et al. Immunological and viral factors associated with the response of vulval intraepithelial neoplasia to photodynamic therapy. Cancer Res 2001;61:192-6.

10. Baseman JG, Koutsky LA. The epidemiology of human papillomavirus infections. J Clin Virol 2005;32(Suppl 1):S16-24

11. Hildesheim A, Wang SS. Host and viral genetics and risk of cervical cancer: a review. Virus Res 2002;89:229-40.

12. Molijn A, Kleter B, Quint W, van Doorn L. Molecular diagnosis of human papillomavirus (HPV) infections. J Clin Virol 2005;32(Suppl 1):S43-51.

13. Nicol AF, Fernandes AT, Bonecini-Almeida Mda G. Immune response in cervical dysplasia induced by human papillomavirus: the influence of human immunodeficiency virus-1 co-infection-review. Mem Inst Oswaldo Cruz 2005;100:1-12.

14. Mota F, Rayment N, Chong S, Singer A, Chain B. The antigen-presenting environment in normal and human papillomavirus (HPV)-related premalignant cervical epithelium. Clin Exp Immunol 1999; 116:33-40.

15. Matthews K, Leong CM, Baxter L, Inglis E, Yun K, Backstrom BT, et al. Depletion of Langerhans cells in human papillomavirus type 16 -infected skin is associated with E6-mediated down regulation of Ecadherin. J Virol 2003;77:8378-85.
16. Niedergang F, Didierlaurent A, Kraehenbuhl JP, Sirard JC. Dendritic cells: the host Achille's heel for mucosal pathogens? Trends Microbiol 2004;12:79-88.

17. Kalinski P, Hilkens CM, Wierenga EA, Kapsenberg ML. T-cell priming by type-1 and type- 2 polarized dendritic cells: the concept of a third signal. Immunol Today 1999;20:561-7.

18. Wang HY, Lee DA, Peng G, Guo Z, Li Y, Kiniwa YF, et al. Tumor specific human $\mathrm{CD} 4+$ regulatory $\mathrm{T}$ cells and their ligands: implications for immunotherapy. Immunity 2004;20:107-18.

19. Cho YS, Kang JW, Cho M, Cho CW, Lee S, Choe YK, et al. Down modulation of IL-18 expression by human papillomavirus type $16 \mathrm{E} 6$ oncogene via binding to IL-18. FEBS Lett 2001;501:139-45.

20. Yang R, Wheeler CM, Chen X, Uematsu S, Takeda $\mathrm{K}$, Akira S, et al. Papillomavirus capsid mutation to escape dendritic cell-dependent innate immunity in cervical cancer. J Virol 2005;79:6741-50.

21. Delvenne P. Immunologic response to (pre)neoplastic cervical lesions associated with human papillomavirus. Bull Mem Acad R Med Belg 2005;160:287-93.

22. Zhang B, Li P, Wang E, Brahmi Z, Dunn KW, Blum JS, et al. The E5 protein of human papillomavirus type 16 perturbs MHC class II antigen maturation in human foreskin keratinocytes treated with interferongamma. Virology 2003;310:100-8.

23. Nees M, Geoghegan JM, Munson P, Prabhu V, Liu Y, Androphy E, et al. Human papillomavirus type 16 E6 and E7 proteins inhibit differentiation-dependent expression of transforming growth factor beta2 in cervical keratinocytes. Cancer Res 2000;60:4289-98.

24. Little AM, Stern PL. Does HLA type predispose some individuals to cancer? Mol Med Today 1999; 5:337-42.

25. Ferenczy A, Coutlée F, Franco E, Hankins C. Human papillomavirus and HIV coinfection and the risk of neoplasias of the lower genital tract: a review of recent developments. Can Med Assoc J 2003;169:431-4.

26. Wentzensen N, Vinokurova S, von Knebel Doeberitz M. Systematic review of genomic integration sites of human papillomavirus genomes in epithelial dysplasia and invasive cancer of the female lower genital tract. Cancer Res 2004;64:3878-84.

27. Quayle AJ. The innate and early immune response to pathogen challenge in the female genital tract and the pivotal role of epithelial cells. J Reprod Immunol 2002;57:61-79. 
28. Wang SS, Hildesheim A. Chapter 5: Viral and host factors in human papillomavirus persistence and progression. $\mathrm{J}$ Natl Cancer Inst Monogr 2003;31:35-40.

29. Chang YE, Laimins LA. Microarray analysis identifies interferon-inducible genes and Stat-1 as major transcriptional targets of human papillomavirus type 31. J Virol 2000;74:4174-82.

30. Li S, Labrecque S, Gauzzi MC, Cuddihy AR, Wong $\mathrm{AH}$, Pellegrini S, et al. The human papilloma virus (HPV)-18 E6 oncoprotein physically associates with Tyk2 and impairs Jak-STAT activation by interferon alpha. Oncogene 1999;18:5727-37.

31. Buck CB, Day PM, Thompson CD, Lubkowski J, Lu W, Lowy DR, et al. Human alpha-defensins block papillomavirus infection. Proc Natl Acad Sci USA 2006;103:1516-21.

32. Zoodsma M, Nolte IM, Schipper M, Oosterom E, van der Steege G, de Vries EG, et al. Interleukin-10 and Fas polymorphisms and susceptibility for (pre)neoplastic cervical disease. Int J Gynecol Cancer 2005;15 (Suppl 3):282-90.

33. Scott M, Nakagawa M, Moscicki AB. Cell-mediated immune response to human papillomavirus infection. Clin Diagn Lab Immunol 2001;8:209-20.

34. Janssen EM, Lemmens EE, Wolfe T, Christen U, von Herrath MG, Schoenberger SP. CD4+ T cells are required for secondary expansion and memory in CD8+ T lymphocytes. Nature 2003;421:852-6.

35. Stanley M. Immune responses to human papillomavirus. Vaccine 2006;24(Supl 1):S16-22.

36. Steele JC, Mann CH, Rookes S, Rollason T, Murphy $\mathrm{D}$, Freeth $\mathrm{MG}$, et al. T-cell responses to human papillomavirus type 16 among women with different grades of cervical neoplasia. Br J Cancer 2005;93: 248-59.

37. Kaech SM, Wherry EJ, Ahmed R. Effector and memory T-cell differentiation: implications for vaccine development. Nat Rev Immunol 2002;2:251-62.

38. Santin AD, Hermonat PL, Ravaggi A, ChirivaInternati M, Zhan D, Pecorelli S, et al. Induction of human papillomavirus-specific CD4(+) and CD8(+) lymphocytes by E7-pulsed autologous dendritic cells in patients with human papillomavirus type 16- and 18-positive cervical cancer. J Virol 1999;73:5402-10.

39. de Gruijl TD, Bontkes HJ, Walboomers JMM, Stukart MJ, Doekhie FS, Remmink AJ, et al. Differential T helper cell responses to human papillomavirus type 16
E7 related to viral clearance or persistence in patients with cervical neoplasia: a longitudinal study. Cancer Res 1998;58:1700-6.

40. van der Burg SH, Ressing ME, Kwappenberg KM, de Jong A, Straathof K, de Jong J, et al. Natural Thelper immunity against human papillomavirus type 16 (HPV16) E7-derived peptide epitopes in patients with HPV16-positive cervical lesions: identification of 3 human leukocyte antigen class II-restricted epitopes. Int J Cancer 2001;91:612-8.

41. Nakagawa M, Stites DP, Patel S, Farhat S, Scott M, Hills NK, et al. Persistence of human papillomavirus type 16 infection is associated with lack of cytotoxic $\mathrm{T}$ lymphocyte response to the E6 antigens. J Infect Dis 2000;182:595-8.

42. Ressing ME, van Driel WJ, Brandt RM, Kenter GG, de Jong JH, Bauknecht T, et al. Detection of T helper responses, but not of human papillomavirus-specific cytotoxic $\mathrm{T}$ lymphocyte responses, after peptide vaccination of patients with cervical carcinoma. J Immunother 2000;23:255-66.

43. Youde SJ, Dunbar PR, Evans EM, Fiander AN, Borysiewicz LK, Cerundolo V, et al. Use of fluorogenic histocompatibility leukocyte antigenA*0201/HPV 16 E7 peptide complexes to isolate rare human cytotoxic T-lymphocyte- recognizing endogenous human papillomavirus antigens. Cancer Res 2000;60:365-71.

44. Evans EML, Man S, Evans AS, Borysiewicz LK. Infiltration of cervical cancer tissue with human papillomavirus-specific cytotoxic $\mathrm{T}$ lymphocytes. Cancer Res 1997;57:2943-50.

45. Frazer IH. Prevention of cervical cancer through papillomavirus vaccination. Nat Rev Immunol 2004;4:46-54.

46. Welters MJ, de Jong A, van den Eeden SJ, van der Hulst JM, Kwappenberg KM, Hassane S, et al. Frequent display of human papillomavirus type 16 E6-specific memory T-helper cells in the healthy population as witness of previous viral encounter. Cancer Res 2003;63:636-41.

47. Carter JJ, Koutsky LA, Hughes JP, Lee SK, Kuypers J, Kiviat N, et al. Comparison of human papillomavirus types 16, 18, and 6 capsid antibody responses following incident infection. J Infect Dis 2000;181:1911-9.

48. Orozco JJ, Carter JJ, Koutsky LA, Galloway DA. Humoral immune response recognizes a complex 
set of epitopes on human papillomavirus type $6 \mathrm{~L} 1$ capsomers. J Virol 2005;79:9503-14.

49. Ho GY, Studentsov YY, BIerman R, Burk RD. Natural history of human papillomavirus type 16 viruslike particle antibodies in young women. Cancer Epidemiol Biomarkers Prev 2004;13:110-6.

50. Viscidi RP, Schiffman M, Hildesheim A, Herrero R, Castle PE, Bratti MC, et al. Seroreactivity to human papillomavirus (HPV) types 16, 18 or 31 and risk of subsequent HPV infection: results from a populationbased study in Costa Rica. Cancer Epidemiol Biomarkers Prev 2004;13:324-7.

51. Jochmus-Kudielka I, Schneider A, Braun R, Kimmig R, Koldovsky U, Schneweis KE, et al. Antibodies against the human papillomavirus type 16 early proteins in human sera: correlation of anti-E7 reactivity with cervical cancer. J Natl Cancer Inst 1989;81:1698-704.

52. Holmgren SC, Patterson NA, Ozbun MA, Lambert PF. The minor capsid protein L2 contributes to two steps in the human papillomavirus type 31 life cycle. J Virol 2005;79:3938-48.

53. Rivera R, Delgado J, Painel V, Barrero R, Larraín A. Mecanismo de infección y transformación neoplásica producido por virus papiloma humano en el epitelio cervical. Rev Chil Obstet Ginecol 2006;71:135-40.

54. Raj K, Berguerand S, Southern S, Doorbar J, Beard P. E1 empty set E4 protein of human papillomavirus type 16 associates with mitochondria. J Virol 2004;78:7199207.

55. Keating PJ, Cromme FV, Duggan-Keen M, Snidjers PJ, Walboomers TM, Hunter RD, et al. Frequency of down-regulation of individual HLA-A and -B alleles in cervical carcinomas in relation to TAP-1 expression. Br J Cancer 1995;72:405-11.

56. Koopman LA, Corver WE, van Der Slik AR, Giphart MJ, Fleuren GJ. Multiple genetic alterations cause frequent and heterogeneous human histocompatibility leukocyte antigen class I loss in cervical cancer. J Exp Med 2000;191:961-76.

57. Fausch SC, Fahey LM, Da Silva DM, Kast WM. Human papillomavirus can escape immune recognition through Langerhans cell phosphoinositide 3-kinase activation. J Immunol 2005;174:7172-8.

58. Burchell AJ, Winer RL, de Sanjose S, Franco EL. Chapter 6: Epidemiology and transmission dynamics of genital HPV infection. Vaccine 2006;24(Suppl 3): S52-61. 